\section{Oral care for socially excluded patients}

Dental service providers and oral health promotion providers are being asked by England's Chief Dental Officer (CDO) Sara Hurley to get in touch and share their experiences about working with socially excluded populations.

The CDO wants to hear from these professionals if they provide dental care or oral health promotion to marginalised groups.

The Office of the CDO is working in collaboration with King's College London to map and find out more about such services with a view to sharing best practice.

All professionals carrying out such work, who may be in Community Dental Services or General Dental Services, in NHS or private practice, or in third sector organisations, are being asked to complete a survey.

Their work could include dental services designed to reach homeless and vulnerably housed populations, sex workers, vulnerable migrants, Gypsy or Roma Travellers, people with substance use disorders and other groups that may be considered marginalised or socially excluded.

In addition to the office of the $\mathrm{CDO}$ and King's College London, other contributors to the development of the survey include the BDA England Community Dental Services Committee, the British Association for the Study of Community Dentistry, Public Health England London, Groundswell, Queen Mary's University London and researchers in the field of social exclusion.

The survey is open until 31 October 2018 and can be found at: https:// kcldental.qualtrics.com/jfe/form/ SV_4VHLQqFpL1sLht3.

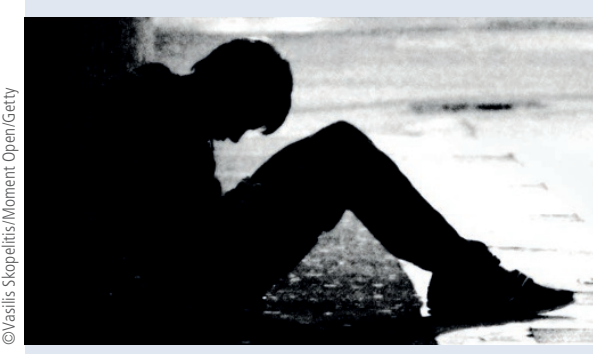

\title{
Enhanced role for oral health in imminent NHS long-term plan
}

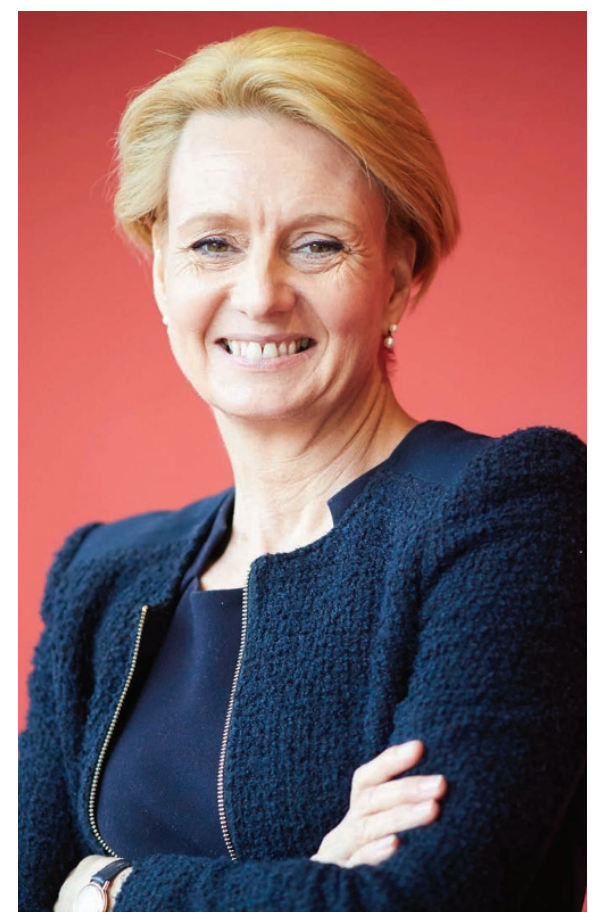

The imminent 10-year plan for the NHS in England looks likely to contain a high focus on improving oral health amongst patients, according to England's Chief Dental Officer (CDO).

CDO Sara Hurley, speaking at the recent BDIA Dental Showcase 2018 conference held in London, said she and her team, were 'making inroads' to the forthcoming NHS long-term plan due to be published in November, and was confident that ministers and officials had listened to the calls for oral health to be seen as a priority.

The health ministers had all continued to declare their commitment to maintaining and improving oral health and supporting the oral health agenda, Hurley told the audience during a speech at the conference on 4 October 2018

'There is a recognition that where we have traditionally tried to use a single silver bullet and focus energies just in one dimension, we need a much more comprehensive approach in working across health and across the social care divide,' said Hurley.

'We operate in a very fragmented way. We need to try to "put the mouth back into the body" by working with those in cardiovascular, in mental health, across NHS England, in the training and education arena, and thinking about the policies that might be delivered by a general medical practitioner and his team.'

There were constraints - fiscal, legislative and regulatory - which affected the pace of change and improvement, she said, as well as the huge current focus on Brexit, but added: 'We have to choose our timing well and the NHS long-term plan has actually come at a pivotal moment in the emergence of the dental profession working much more cohesively and making its networks integral to health.

'The big piece of work where we are making major inroads into is the NHS long-term plan.

'There is a critical opportunity with the NHS long-term plan, but we have opportunities also presenting themselves in the profession and I look to the expansion of FGDP $\mathrm{UK}$ as its looking at broadening its remit into the DCP arena bringing the profession together as one.

'We are learning that we have friends in high places and friends across health and social care who are now actively seeking out oral health advice for their policies and oral health expertise in delivering care for their patients.

'The vision of increasing access and improving oral health, reducing health inequalities has made it into a much more tangible plan. We are now clearly aligning the activities within the profession with what is happening with HEE [Health Education England], with what is happening in the [dental] contract reform arena, and with what is happening in the digital arena.'

Hurley also urged the profession to accept the need for more career flexibility as the profession's profile was changing.

'There is an appetite to see that there are flexible opportunities for anybody in dental care, she told the audience.

'To put this in context, $59 \%$ of the dentist profession under the age of 35 are women and women are looking for a life balance that goes with running a family life and running life. That's not exclusive to women and we are also seeing the gentlemen in the profession saying they want to have a flexible career. We have to listen to the younger generation.' 